\title{
Damage evolution around white etching layer during uniaxial loading
}

\author{
Jessop, Casey; Ahlström, Johan; Persson, Christer; Zhang, Yubin
}

Published in:

Fatigue and Fracture of Engineering Materials and Structures

Link to article, DOI:

10.1111/ffe.13044

Publication date:

2020

Document Version

Peer reviewed version

Link back to DTU Orbit

Citation (APA):

Jessop, C., Ahlström, J., Persson, C., \& Zhang, Y. (2020). Damage evolution around white etching layer during uniaxial loading. Fatigue and Fracture of Engineering Materials and Structures, 43(1), 201-208.

https://doi.org/10.1111/ffe.13044

\section{General rights}

Copyright and moral rights for the publications made accessible in the public portal are retained by the authors and/or other copyright owners and it is a condition of accessing publications that users recognise and abide by the legal requirements associated with these rights.

- Users may download and print one copy of any publication from the public portal for the purpose of private study or research.

- You may not further distribute the material or use it for any profit-making activity or commercial gain

- You may freely distribute the URL identifying the publication in the public portal

If you believe that this document breaches copyright please contact us providing details, and we will remove access to the work immediately and investigate your claim 
Damage evolution around white etching layer during uniaxial loading

Casey Jessop ${ }^{\star 1}$, Johan Ahlström¹, Christer Persson ${ }^{1}$, Yubin Zhang ${ }^{2}$

${ }^{1}$ Department of Industrial and Materials Science, Chalmers University of Technology, Sweden

2 Department of Mechanical Engineering, Technical University of Denmark, $2800 \mathrm{Kgs}$.

Lyngby, Denmark

*corresponding author: casey.jessop@chalmers.se 


\section{Abstract}

Rolling contact fatigue cracks and thermally induced defects are common problems in the railway industry especially as demands for increasing loads, speeds, and safety, continue to rise. Often the two types of defects are found together in the field, however whether one causes the other to occur is not completely agreed upon. The effect of thermal damage, in the form of a martensite spot on pearlitic steel test bars, on the fatigue life in uniaxial low cycle fatigue experiments was investigated by the authors ${ }^{1}$. However, the focus of the current work was to characterize the damage evolution from the low cycle fatigue (LCF) tests and correlate the crack initiation and propagation with the initial thermal damage. Residual stress measurements, digital image correlation, and X-ray tomography were used to characterize the effects of the thermal damage before, during, and after fatigue testing, respectively. It was found that the thermal damage causes strain accumulation and crack initiation at the interface between the two materials, and that thermally damaged samples eventually fail at a lower number of cycles than reference samples.

Keywords: Rolling contact fatigue, white etching layer, strain localization, X-ray tomography, digital image correlation, residual stresses

Nomenclature:

$\mathrm{N}_{f} \quad$ number of cycles to failure

$\mathrm{R} \quad$ load ratio or stress ratio $=\sigma_{\mathrm{min}} / \sigma_{\max }$ in a cycle

$\varepsilon_{\mathrm{a}} \quad$ total strain amplitude

$\varepsilon_{\mathrm{pa}} \quad$ plastic strain amplitude

\section{Introduction}

The problem of rolling contact fatigue (RCF) is one which is widespread in the railway industry. The repeated application of loads from rolling contact between wheels and rails causes severe plastic deformation of the topmost layer of the material, which eventually leads to crack formation when the fatigue damage has exceeded some limit ${ }^{2,3}$. The presence of larger cracks on the rail and wheel surfaces are a major economic concern and safety risk in the industry when it comes to maintenance operations and complete component failure. In addition to RCF cracking, the surface 
deformation also leads to deformation hardening and builds up residual stresses in the material ${ }^{4}$. The residual stresses which result from operation in the rails and wheels have been extensively studied 5 . During operation, compressive residual stresses are formed in the surface of the rails, due to plastic deformation and work hardening arising from rolling contact loads which the rails are subjected to ${ }^{2,4,6,7}$. These residual stresses are beneficial for fatigue life as they generally decrease the crack propagation rate. However, some $10-20 \mathrm{~mm}$ below the surface, residual stresses become tensile to maintain equilibrium. This can have harmful effects on the crack propagation at this depth, and could contribute to complete fracture of the rails.

Furthermore, a major damage characteristic which occurs on rail and wheel surfaces is thermal damage in the form of so-called white etching layers (WELs). WELs form on the surface of the rails and wheels due to wheel/rail interactions which, by frictional heating, temporarily increase the temperature above the effective austenitization temperature ${ }^{8}$. After rapid cooling, a thin layer of martensite forms on the surface of the component (called WEL due to the white appearance under the optical microscope after Nital etching, see Figure 1). It should be mentioned that also thinner WEL layers in the order of $10 \mu \mathrm{m}$ are commonly found on rails, while the type referred to in this study arise from occasional skid events like wheel burns and have a thickness of some 200-500 $\mu \mathrm{m}$. Such WEL defects are mainly found close to insulation joints, signals, stations and on metro lines. As opposed to the more soft and ductile pearlite bulk material, the martensite plug or layer formed is hard and brittle. The WEL essentially acts as a stress-raiser (similar to a hard inclusion) due to the different behaviour of the pearlite and the martensite, which leads to strain accumulation at their interface during RCF loading 9 . It was shown in a previous numerical study that similar WEL spots on the surface of wheels or rails drastically increases the fatigue damage near the WEL border; especially pronounced with off-center RCF loadings ${ }^{10}$. That is, the presence of WEL leads to increased risk of crack initiation and eventual growth by RCF mechanisms. There are generally two types of cracks associated with WEL: cracks growing at the interface of the WEL and the bulk material (Figure 1a), and cracks growing through the WEL (Figure 1b) ${ }^{10}$. Figure 1a shows the tendency of cracks to branch at the interface and propagate perpendicular to the original crack, below the WEL. 

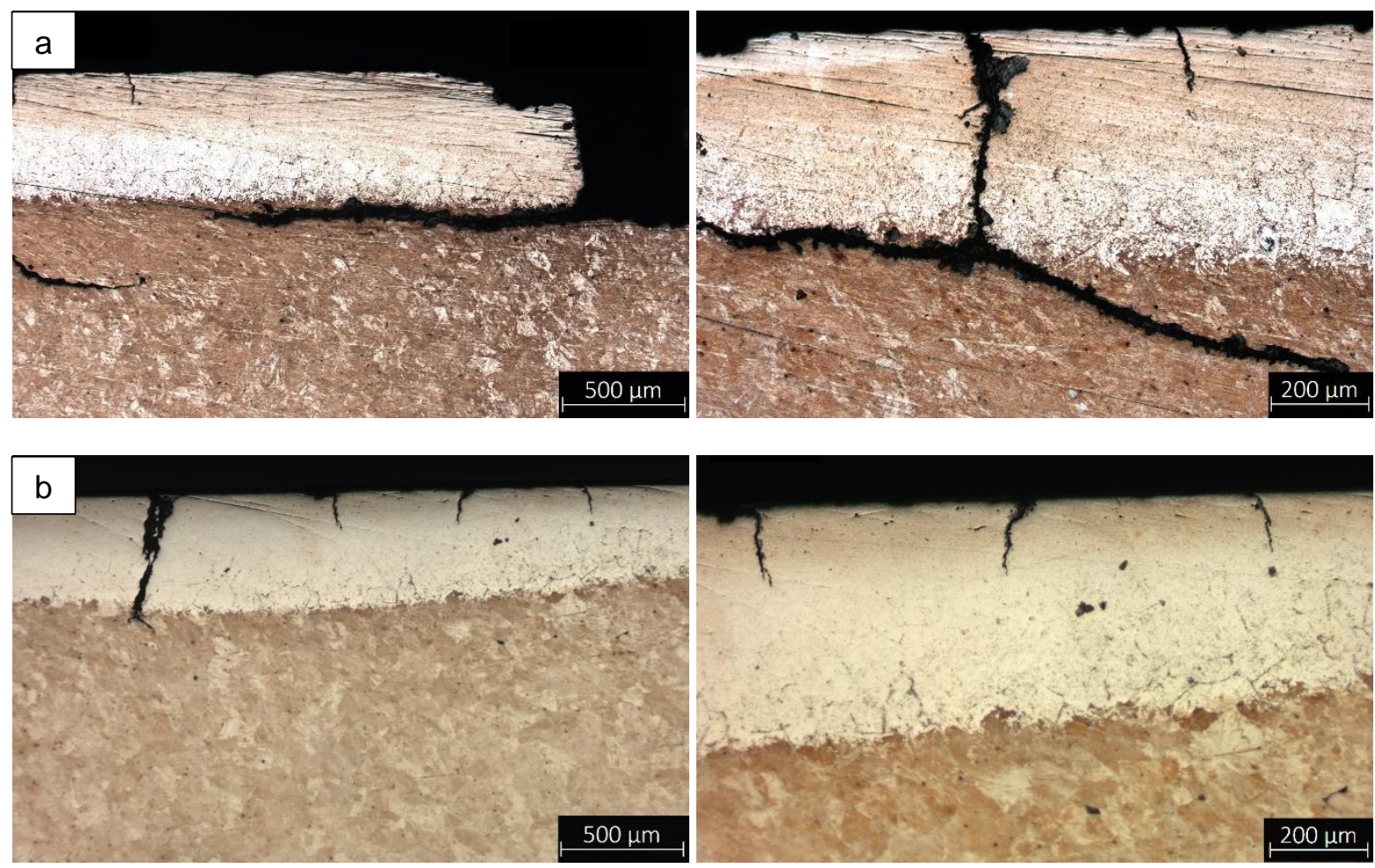

Figure 1. (a) Cracks growing at interface of WEL and bulk, and (b) growing through WEL.

The residual stresses arising in the rail due to the effect of thermal damage is evidently an important consideration ${ }^{11}$. As the surface layer is heated, its volume increases by thermal expansion and the flow stress generally decreases with temperature. If plastic deformation in compression occurs as a consequence, this can lead to tensile residual stresses upon cooling. If WELs form as a result of phase transformation to austenite, further contributions to residual stresses are introduced into the material. Specifically, the small volume of material which becomes austenite, rapidly cools to form martensite, which after cooling has a lower density than the surrounding pearlite. The volume increase can introduce compressive residual stresses in the $\mathrm{WEL}^{12,13}$. The depth of residual stresses formed by this mechanism is more shallow than the typical RCF loading induced residual stresses.

The effect of thermal damage, in the form of a WEL spot, on the fatigue life in uniaxial cyclic straining was investigated by the authors. Despite the differences from RCF loadings, it is considered useful for basic mechanisms, since local strains and stresses are more easily deduced from such experiments, and can be compared with stress concentrations at inclusions and similar ${ }^{14,15}$. The full results from the fatigue experiments are previously published ${ }^{1}$. The aim of the present work is to characterize 
the damage evolution and crack formation during low cycle fatigue tests for pearlitic R260 rail steel test bars without and with initial thermal damage. The focus is the characterization of the damage at, and around, the initial thermal damage (WEL) evaluated before, during, and after the uni-axial fatigue loading using residual stress measurements, digital image correlation (DIC), and X-ray tomography, respectively.

\section{Experimental}

The current study investigates cracks initiated from thermally damaged spots made on test bars of $\mathrm{R} 260$ rail steel, with composition shown in Table 1. The initial thermal damage was in the form of a WEL formed by laser heating, with thickness close to 200 $\mu \mathrm{m}$ and diameter approximately $1.5 \mathrm{~mm}$. The experiments on crack initiation on test bars were performed using a MTS 809 servo-hydraulic tension-torsion test machine, run in uniaxial mode, and are summarized in a previous work ${ }^{1}$. A polished test bar with an artificially produced initiation site is shown in Figure 2. In order to characterize the damage throughout the fatigue experiments, microscopy, residual stress measurements, digital image correlation (DIC), and X-ray tomography were used.

Table 1. Composition of rail steels examined, in weight $\%$.

\begin{tabular}{|l|l|l|l|l|l|l|l|}
\hline Element & C & Mn & Si & P & S & Cr & Fe \\
\hline R260 & 0.72 & 1.04 & 0.31 & 0.006 & 0.010 & 0.02 & Balance \\
\hline
\end{tabular}
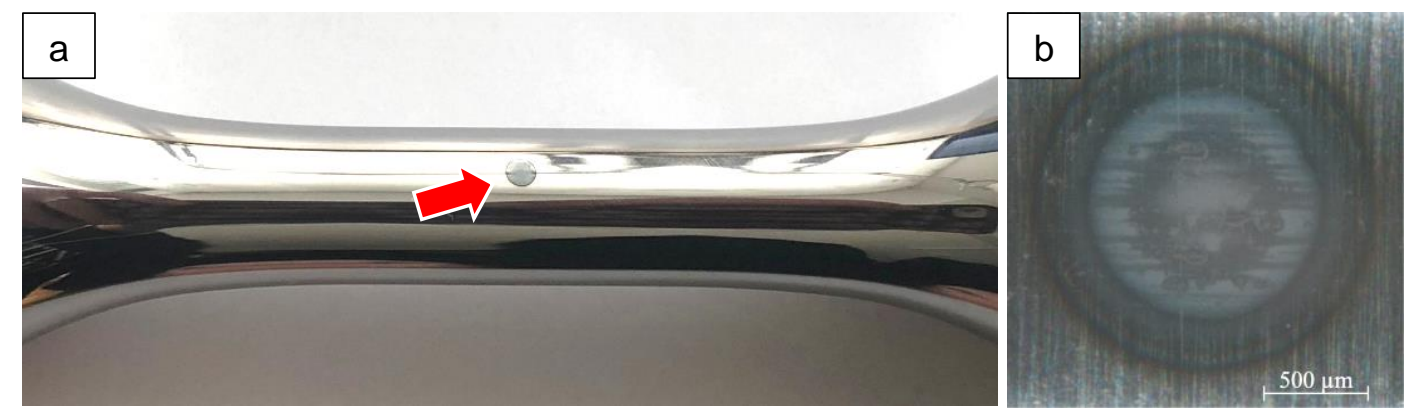

Figure 2. (a) Initial thermal damage (WEL) on polished test bar, and (b) close-up of WEL spot

\subsection{Residual stress measurements}

Residual stress measurements were done using a Stresstech Xstress 3000 X-ray machine with the $\sin ^{2} \psi$ method and $\mathrm{Cr}$ Ka-radiation, with $1 \mathrm{~mm}$ collimator used for measurements on test bars with and without initial thermal damage. The detectors were positioned at $2 \theta \approx 156^{\circ 14}$. The measurements were run with the inclination angle 
$\psi$ between $-45^{\circ}$ and $+45^{\circ}$, using nine equal steps in $\sin ^{2} \psi$ (i.e. $0^{\circ}, \pm 21^{\circ}, \pm 30^{\circ}, \pm 38^{\circ}$, $\left.\pm 45^{\circ}\right)$, and in 3 directions $\left(\Phi=0^{\circ}, 45^{\circ}\right.$, and $\left.90^{\circ}\right)$.

\subsection{Fatigue tests and DIC}

Uniaxial strain-controlled fatigue tests were performed at room temperature, at constant total strain rate of $10^{-2} \mathrm{~s}^{-1}$, and at three constant, symmetric, strain amplitudes: $0.4 \%, 0.6 \%$, and $1.0 \%$. Test bars were machined, ground and polished before testing. Two different conditions were tested: smooth (un-notched) and with initial thermal damage, Figure 2. The un-notched specimens were tested to provide a basis for fatigue behaviour of the material. Two tests were performed for each strain amplitude and for both conditions.

An ARAMIS 3D motion and deformation sensor system, based on digital image correlation (DIC), was used on one additional fatigue test in order to visually capture the strain evolution on the test bar surface during uniaxial cyclic loading. The technique is based on tracking the deformation in the test bar by comparing images at a given interval to a reference image. The strain field is deduced from the analysis of the displacement field of the specific details painted onto the surface. The test bar is spray painted to obtain a uniform and random speckle pattern on the surface. The camera was focused on the center of the test bar where the WEL spot was present. Due to the different flow stresses, it can be predicted that the WEL spot will act as a stress-raiser during uniaxial loading, and this will affect plastic strain initiation and accumulation. A snapshot was taken at the maximum load in tension for each cycle. The LCF test was run in stress control, with stress amplitude $600 \mathrm{MPa}$ at $R=-1$. The main reason for using stress control, is that the clip on extensometer normally used, shields the visibility of the sample surface. The effect on the fatigue process has been demonstrated to be minor ${ }^{18}$.

\subsection{Characterization of test bars after failure}

Characterization of the test bars after fatigue testing was done using a Zeiss SteREO Discovery V20 stereomicroscope and a Leica light optical microscope. The surfaces of the bars were examined for cracks and other defects, and in particular, the area near the initial thermal damage was examined for signs of crack initiation. The test bars with WEL were heat treated for one hour at $300^{\circ} \mathrm{C}$ to oxidize the fractured section for better visibility when broken apart to reveal the fatigue crack propagation. Furthermore, X- 
ray tomography was done on one test bar after fatigue testing using a Zeiss Xradia 520 Versa instrument. The X-ray energy was polychromatic up to $150 \mathrm{kV}$ from a tungsten target and 2801 projections of each region were acquired. 3D density maps were reconstructed by a standard filtered back-projection method to $1 \mathrm{k} \times 1 \mathrm{k} \times 1 \mathrm{k}$ pixel volumes with a voxel size of $1.75 \mu \mathrm{m}$. The test bar was still intact, and the X-ray tomography allowed non-destructive evaluation of the crack network within the test bar. The purpose of using this technique was to observe the relation between the crack network and the surface initial thermal damage.

\section{Results}

Before fatigue testing, residual stress measurements were done on the smooth and thermally damaged test bars. The results are shown in Figure 3. The smooth test bars have constant compressive residual stresses between -200 and -220 MPa. For the initially damaged test bars, tensile residual stresses are present at the center of the WEL spot, which decrease to similar stable compressive residual stresses of approximately -230 MPa in the unaffected bulk material, some $3 \mathrm{~mm}$ from the center of the WEL.

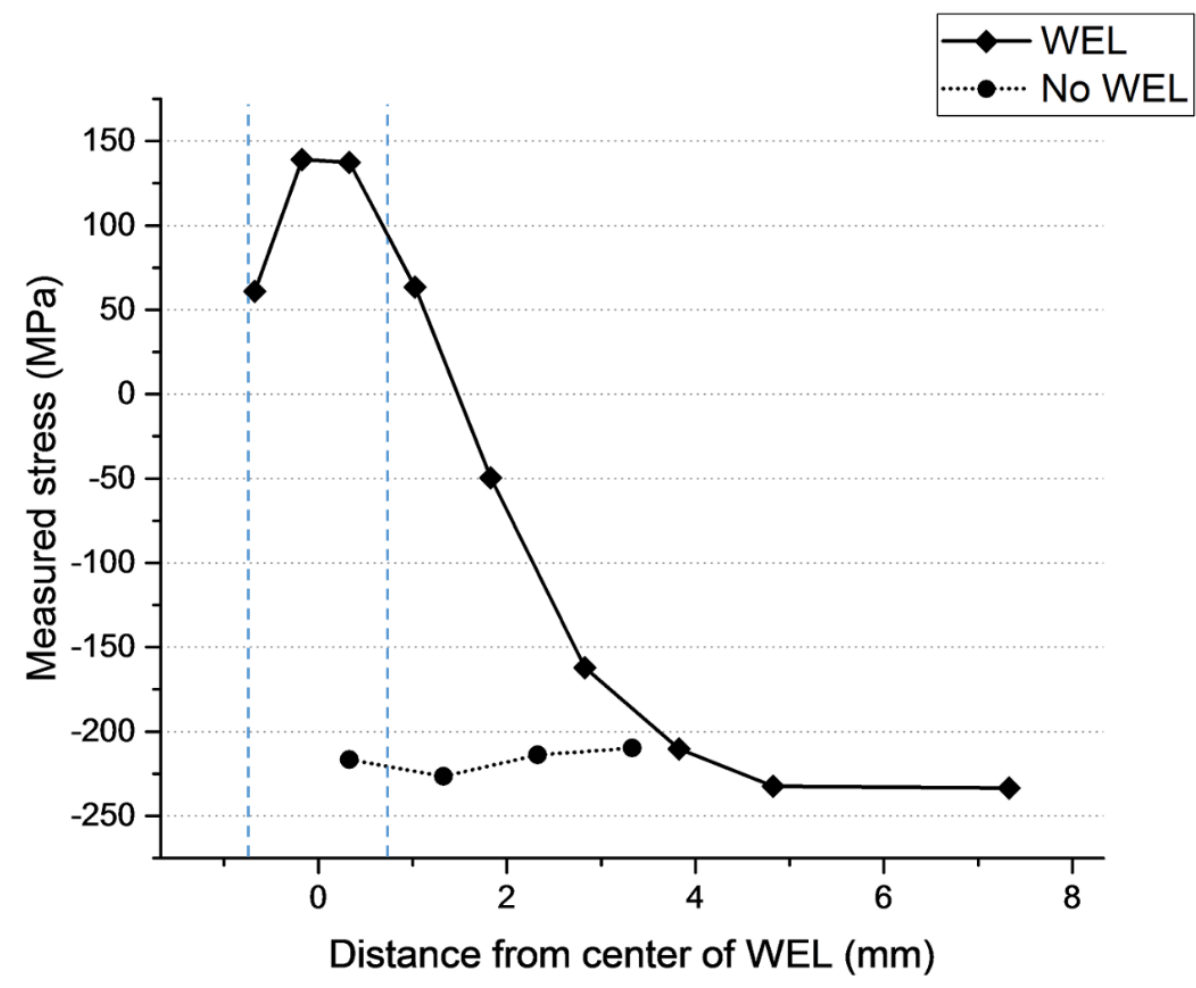

Figure 3. Residual stress measurements along test bars without and with WEL. The vertical dashed lines indicate the approximate boundaries of the WEL spot. 
The results from the fatigue tests have been presented and discussed in earlier work ${ }^{1}$. Figure 4 is a Coffin-Manson plot for the performed experiments showing that the presence of the initial thermal damage on the test bars decreased the fatigue life in all tests. The effect is more pronounced for fatigue tests run with higher strain amplitude (Table 2).

Table 2. Average fatigue lives for smooth and thermally damaged test bars.

\begin{tabular}{|l|l|l|l|l|}
\hline \multicolumn{3}{|l|}{ Smooth } & WEL & Decrease \\
\hline$\varepsilon_{\mathrm{a}}$ & $\mathrm{N}_{\mathrm{f} \text {,ave }}$ & $\varepsilon_{\mathrm{a}}$ & $\mathrm{N}_{\mathrm{f}, \text { ave }}$ & $\%$ \\
\hline $0.4 \%$ & 12849 & $0.4 \%$ & 11651 & 9.3 \\
\hline $0.6 \%$ & 4438 & $0.6 \%$ & 3601 & 18.9 \\
\hline $1.0 \%$ & 1161 & $1.0 \%$ & 760 & 34.0 \\
\hline
\end{tabular}

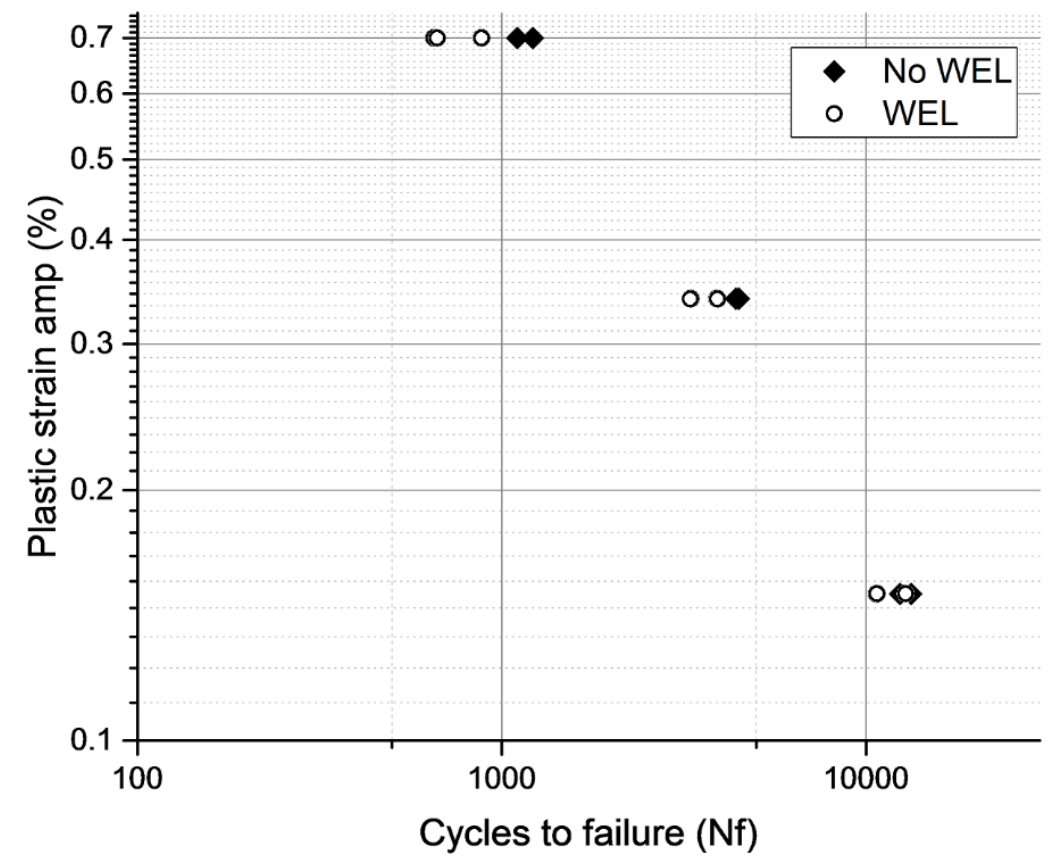

Figure 4. Coffin-Manson plot for uniaxial fatigue tests performed on smooth (diamonds) and thermally damaged (circles) test bars.

During one fatigue test (stress control, $600 \mathrm{MPa}$ ) the evolution of strain on the surface of the test bar, specifically around the WEL spot, was measured using digital image correlation (DIC) equipment. Figure 5 shows the strains around the WEL for the early stages of the fatigue test (Figure 5a) and during the last 4 cycles before failure (Figure $5 b)$. The strain appears in the loading direction at top and bottom of the WEL, at the 
transition between the two different phases (martensite and pearlite). The strain concentration on one side grows larger already from the first cycle, and the strain on the opposite side of the WEL decreases. The dominant crack forms and continues to accumulate strain until the test bar fails at that location. Strains above $20 \%$ were measured around the dominant crack.

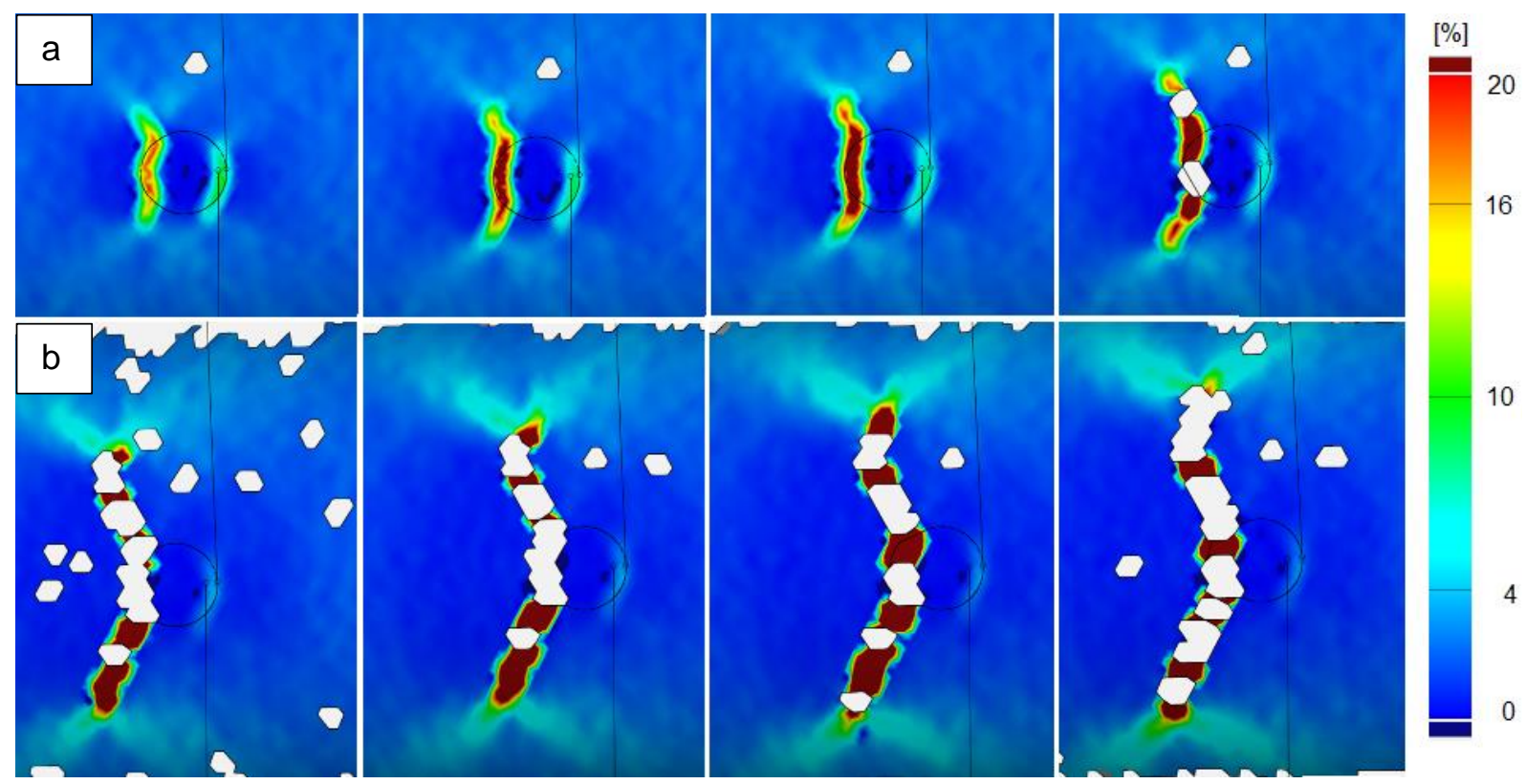

Figure 5. Strain evolution around the WEL during LCF fatigue test (loading in horizontal direction) a) in early stages, and b) during the final 4 cycles before failure, obtained from DIC.

In the smooth specimens, fracture surfaces reveal that the crack propagates through a large part (approximately 20-25\%) of the cross-sectional area before fracture. On the surface of the gauge section, many small cracks and surface texture are seen. However, the cracks formed in the WEL-notched specimens extend largely across the surface, in the vincinity of the WEL (Figure 6). Similar cracks were present for all test bars with thermal damage. After longitudinally cross-sectioning a test bar similar to that shown in Figure 6, it was examined using optical microscopy. Figure 7 shows the crack growing through the WEL, and another small crack initiated at the opposite edge. The cracks propagated approximately $20-25 \%$ of the surface of the test bars for all strain amplitudes tested, similar to the extent of crack propagation in the smooth test bars. 

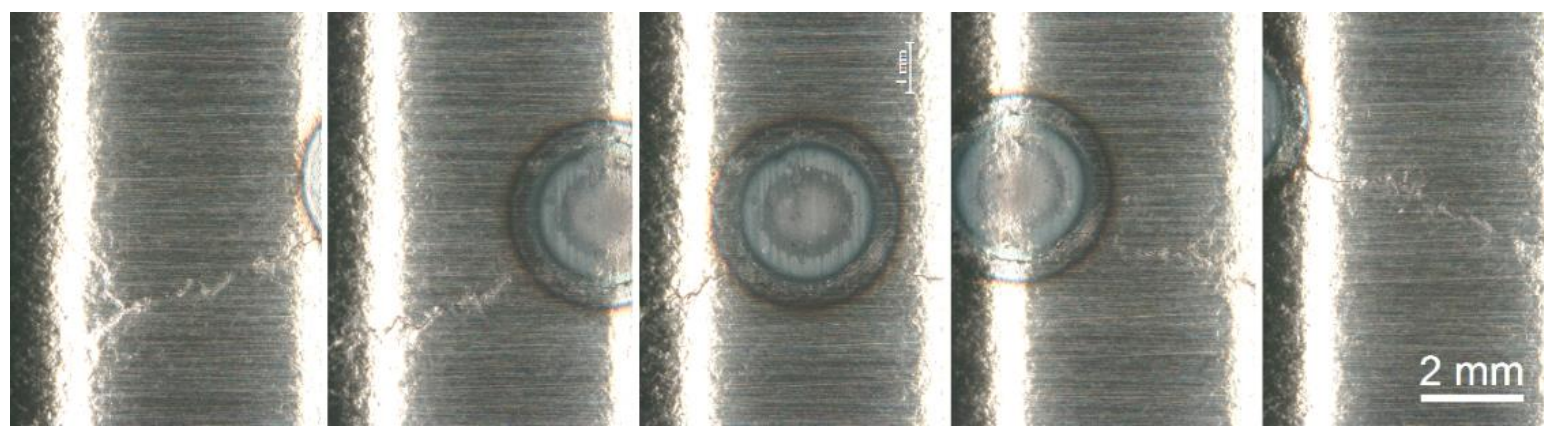

Figure 6. Crack propagation through WEL on fatigue test bar (C02, 1.0\% strain amplitude).
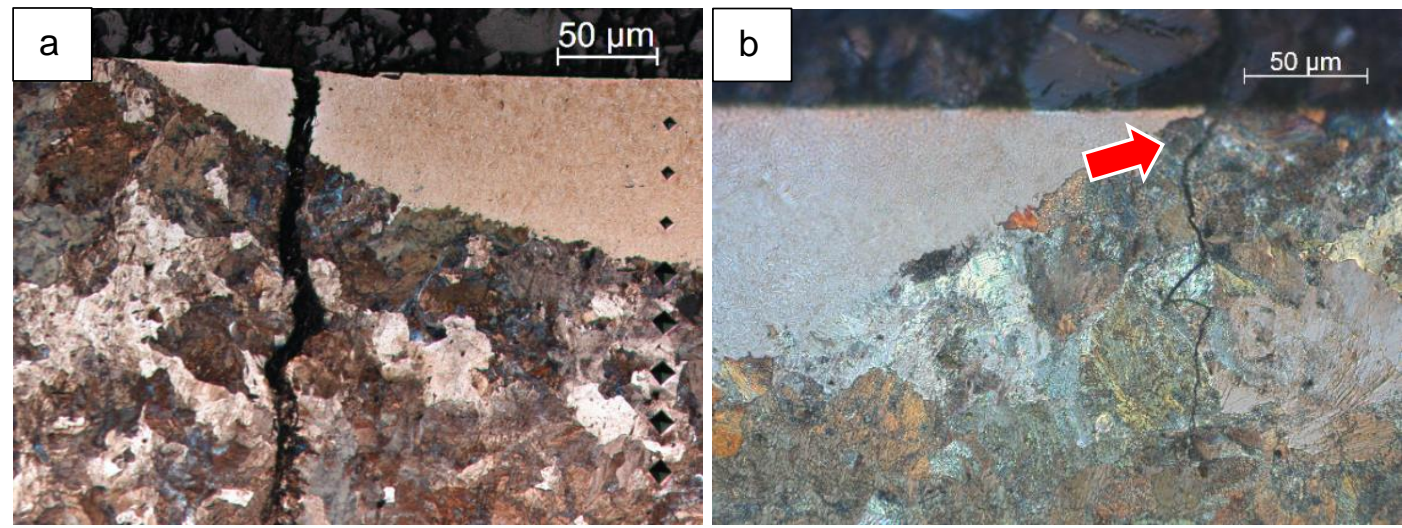

Figure 7. Longitudinal cross-section of WEL on test bar (C01) used in fatigue test. (a) The crack initiated in the WEL and propagated down into the bulk material. (b) A small crack initiated at the edge of the WEL (polarized light in optical microscope).

Additionally, X-ray tomography scans of one of the test bars fatigue tested at $0.6 \%$ strain amplitude show the crack extending as a planar network perpendicular to the loading direction (Figure 8a,b). Figure 8 shows the extent of the crack along the surface of the test bar, as well as an X-ray tomograph of the crack network within the test bar. A high resolution scan (Figure 8c) focused on the center of the test bar shows the crack following the circular shape of the WEL on the surface of the test bar as a dashed line. It can be seen that, according to the approximate location of the WEL spot, the crack network follows the circular shape along the surface of the test bar. 

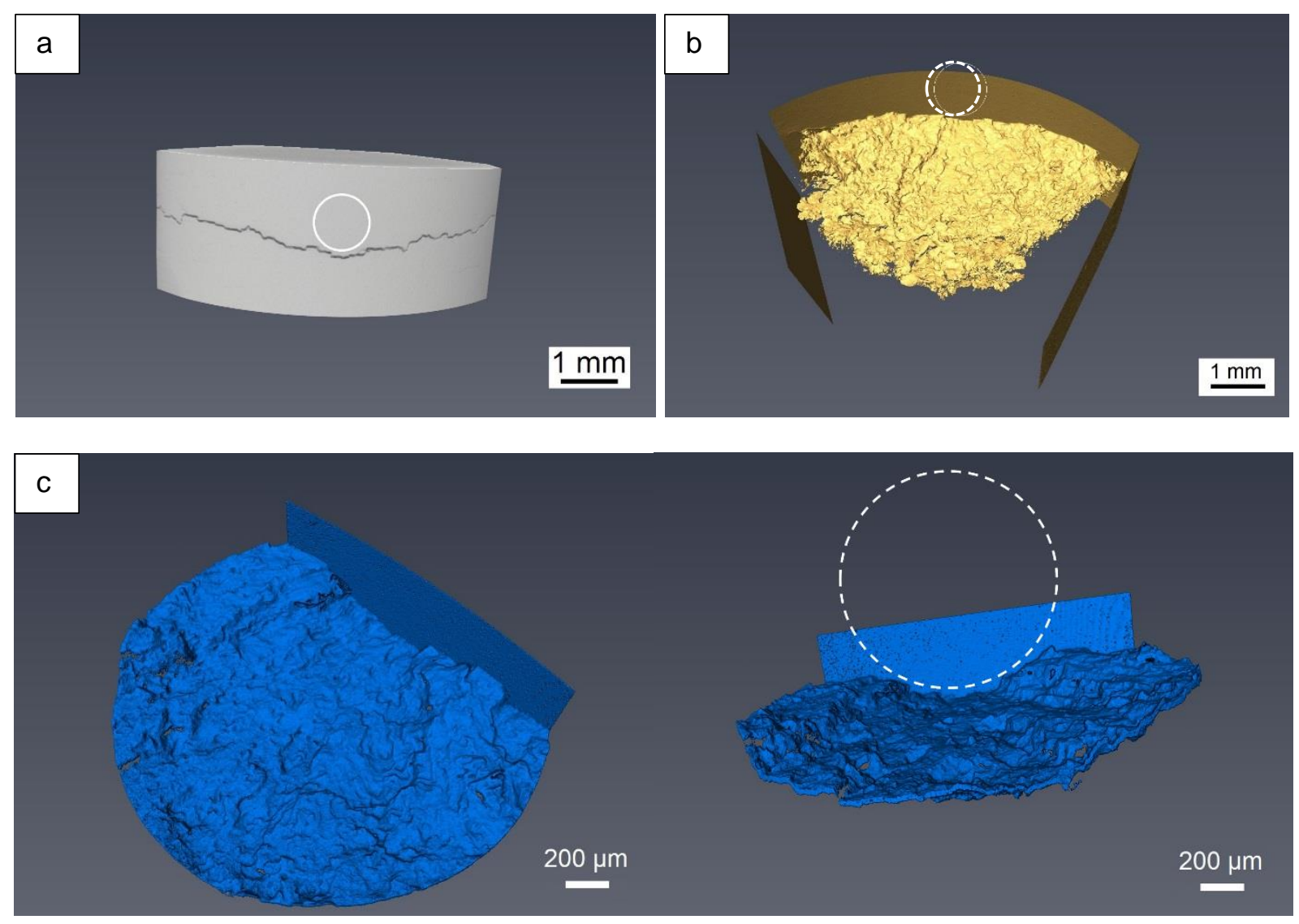

Figure 8. (a) X-ray tomograph of the extent of the crack on the surface of the test bar, (b) overall scan of the crack network within the test bar, and (c) detail scan near the WEL, showing the crack following the bottom of the WEL spot (dashed line represents the approximated location of the WEL spot).

\section{Discussion}

From the results plotted in Figure 3, it can be seen that the volume within the WEL spot has tensile residual stresses of $\approx 150 \mathrm{MPa}$, and the stresses decrease as the distance from the center of the WEL increases. The effect of the $\approx 1.5 \mathrm{~mm}$ diameter WEL is no longer apparent after some $3 \mathrm{~mm}$ (corresponding to $6 \mathrm{~mm}$ diameter), where the residual stresses match those of the test bar not subjected to laser heating experiments, that is, between -200 and $-220 \mathrm{MPa}$. It should be noted that the surface compressive residual stresses in the test bars are formed in part from the grinding and polishing to mirror finish ${ }^{15,16}$. However, these surface residual stresses do not affect fatigue life since they are very shallow and the plastic strain amplitudes imposed by the outer loading is large enough to cancel out at least the majority of residual stresses already within the first cycle ${ }^{15-17}$. The plastic deformation of the pearlite surrounding the WEL, will regenerate the stress field in every loading, and thus the main 
contribution to changed fatigue life will be due to the discontinuity in flow stress, causing localization of plastic strains.

The effect of increasing the strain amplitude is a decrease in fatigue life. The complete results from the fatigue tests have been discussed in previous work ${ }^{1}$, but are summarized here in Figure 4. It can also be seen that the fatigue life decreases with the presence of the thermal damage on the test bars. This is in agreement with previous studies of the same material ${ }^{18}$.

The effect of the WEL seems more important in the tests run with larger strain amplitudes (Table 2). That is to say, the effect of a notch (or WEL) during LCF is important during crack initiation but not as significant during crack propagation ${ }^{19}$. The crack initiates at, or near the WEL in all but one test, but in all tests (smooth and thermally damaged) the extent of the crack propagation in the fracture surface is the same for a given strain amplitude ${ }^{1}$. Using DIC equipment, the evolution of the strains at either end of the WEL in the direction of loading is clearly seen. This is expected behaviour since the WEL acts as a strain concentration since it creates a discontinuity in the material where the phase changes from pearlite to martensite. It is also anticipated that a crack initiates at the point of highest strain, in the vincinity of the initial thermal damage spot $^{9}$.

The use of X-ray tomography allowed for a 3-dimensional non-destructive evaluation of the crack network inside the test bar with initial thermal damage. The method is complementary to the stereomicroscopy, which provides an exterior visualization of the cracks on the surface of the test bars with WEL. The X-ray tomography scans provide additional information, including showing the crack following the shape of the WEL at the surface, then propagating in a planar direction perpendicular to the loading direction. This is consistent with the strain concentration occuring at both extremities of the WEL spot (in the direction of axial force), which was shown clearly in the DIC results in Figure 5. The presence of softened pearlite microstructure around the WEL 20,21 , as a result of the laser heating experiment and phase transformation, could also influence the location of the crack initiation. Although the effect of the WEL as a stress concentration is important for the crack initiation, the influence of notches is known to be less significant during crack propagation ${ }^{19}$. This is made apparent as the 
fracture surfaces for the smooth test bars and those with initial thermal damage are similar for all strain amplitudes tested.

\section{Conclusions}

The aim of the study was to characterize the damage evolution and crack formation during low cycle fatigue tests for pearlitic R260 rail steel test bars without and with initial thermal damage. The initial thermal damage was in the form of a WEL formed by laser heating. Characterization of the laser-induced WEL on the test bars and rail sections, presented in a previous work ${ }^{1}$, revealed these are similar to those found in the field. Residual stress measurements were done around the WEL formed on test bars, and it was found that the compressive residual stresses from surface finishing are released during the laser heating, and become tensile in the central parts of the WEL.

Uniaxial strain-controlled fatigue tests were done at constant strain amplitudes of $1.0 \%$, $0.6 \%$, and $0.4 \%$. It was found that the presence of initial thermal damage acts as a stress-raiser and decreased the fatigue life for tests run at all strain amplitudes. The failure occurs near the WEL in all but one of the tests with thermally damaged spots, with the crack initiating in the martensite and growing outwards. The strain evolution during the LCF tests was visualized with the use of DIC, which clearly shows the strain concentrations at the top and bottom of the WEL, in the loading direction. X-ray tomography confirmed the crack growth follows the martensite spot from the surface inwards to the center of the test bar.

\section{Acknowledgement}

This work has been a part of research activities within the Centre of Excellence CHARMEC (CHAlmers Railway MEChanics, www.charmec.chalmers.se). It is partly financed within the European Horizon 2020 Joint Technology Initiative Shift2Rail through contract No. 730841.The authors further acknowledge support from MAX4ESSFUN for the Interreg project. Our colleagues Sebastian Almfeldt and Knut Andreas Meyer kindly helped us with the DIC measurements, which was much appreciated by the authors.

\section{References}

[1] C. Jessop, J. Ahlström, and C. Persson, "Crack formation in pearlitic rail steel 
under uniaxial loading: effect of initial thermal damage," in LCF8 Eighth International Conference on Low Cycle Fatigue, 2017, pp. 275-280.

[2] A. F. Bower and K. L. Johnson, "Plastic flow and shakedown of the rail surface in repeated wheel-rail contact," Wear, vol. 144, 1991.

[3] S. L. Grassie, "Squats and squat-type defects in rails: the understanding to date," J. Rail Rapid Transit, vol. 226, pp. 235-242, 2011.

[4] A. Ekberg and E. Kabo, "Fatigue of railway wheels and rails under rolling contact and thermal loading - an overview," Wear, vol. 258, pp. 1288-1300, 2005.

[5] M. Olzak, J. Stupnicki, and S. Bogdanski, "Numerical Modelling of a 3D Rail Rcf 'Squat ' -Type Crack," pp. 923-935, 1998.

[6] H. M. Tournay and J. M. Mulder, "The transition from the wear to the stress regime," Wear, vol. 191, no. 1-2, pp. 107-112, 1996.

[7] A. Ekberg, B. Åkesson, and E. Kabo, "Wheel/rail rolling contact fatigue - Probe, predict, prevent," Wear, vol. 314, no. 1-2, pp. 2-12, 2014.

[8] J. Takahashi, "Atom probe study on microstructure change in severely deformed pearlitic steels: application to rail surfaces and drawn wires," IOP Conf. Ser. Mater. Sci. Eng., vol. 219, 2017.

[9] N. E. Dowling, Mechanical Behavior of Materials, Fourth Edi. Pearson Education, 2013.

[10] R. Andersson, J. Ahlström, E. Kabo, F. Larsson, and A. Ekberg, "Numerical investigation of crack initiation in rails and wheels affected by martensite spots," Int. J. Fatigue, vol. 114, pp. 238-251, 2018.

[11] J. Seo, S. Kwon, H. Jun, and D. Lee, "Numerical stress analysis and rolling contact fatigue of White Etching Layer on rail steel," Int. J. Fatigue, vol. 33, no. 2, pp. 203-211, 2011.

[12] J. Ahlström and B. Karlsson, "Microstructural evaluation and interpretation of the mechanically and thermally affected zone under railway wheel flats," Wear, vol. 232, pp. 1-14, 1999.

[13] J. Ahlström, "Residual stresses generated by repeated local heating events - 
Modelling of possible mechanisms for crack initiation," Wear, vol. 366-367, pp. 180-187, 2016.

[14] I. C. Noyan and J. B. Cohen, Residual Stress Measurement by Diffraction and Interpretation. Springer-Verlag New York Inc., 1987.

[15] A. S. Pandkar, N. Arakere, and G. Subhash, "Ratcheting-based microstructuresensitive modeling of the cyclic hardening response of case-hardened bearing steels subject to Rolling Contact Fatigue," Int. J. Fatigue, vol. 73, pp. 119-131, 2015.

[16] A. S. Pandkar, N. Arakere, and G. Subhash, "Microstructure-sensitive accumulation of plastic strain due to ratcheting in bearing steels subject to Rolling Contact Fatigue," Int. J. Fatigue, vol. 63, pp. 191-202, 2014.

[17] M. E. Fitzpatrick, A. T. Fry, P. Holdway, F. A. Khadil, J. Shackleton, and L. Suominen, "Determination of Residual Stresses by X-Ray Diffraction- Issue 2," National Physical Laboratory, Teddington, Middlesex, United Kingdom, 2005.

[18] J. Ahlström and B. Karlsson, "Fatigue behaviour of rail steel- a comparison between strain and stress controlled loading," Wear, vol. 258, pp. 1187-1193, 2005.

[19] T. Brockhoff, "Grind-Hardening: A Comprehensive View," Ann. CIRP, vol. 48, no. 1, pp. 255-260, 1999.

[20] J. D. Thiele, S. N. Melkote, R. A. Peascoe, and T. R. Watkins, "Effect of CuttingEdge Geometry and Workpiece Hardness on Surface Residual Stresses in Finish Hard Turning of AISI 52100," Trans. ASME, vol. 122, pp. 642-649, 2000.

[21] K. Dalaei, B. Karlsson, and L. Svensson, "Stability of shot peening induced residual stresses and their influence on fatigue lifetime," Mater. Sci. Eng. A, vol. 528, no. 3, pp. 1008-1015, 2011.

[22] M. Sakane, S. Zhang, and T. Kim, "Notch effect on multiaxial low cycle fatigue," Int. J. Fatigue, vol. 33, no. 8, pp. 959-968, 2011.

[23] D. Nikas and J. Ahlström, "Characterization of microstructural changes in near pearlitic steels using orientation imaging microscopy - influence of predeformation on local sensitivity to thermal degradation," in IOP Conf. Series: 
Materials Science and Engineering, 2015, vol. 89.

[24] D. Nikas, J. Ahlström, and A. Malakizadi, "Mechanical properties and fatigue behaviour of railway wheel steels as influenced by mechanical and thermal loadings," Wear, vol. 366-367, pp. 407-415, 2016. 